\title{
Driver Distraction and Stress Detection Systems: A Review
}

\author{
Raymond Ghandour, Bilel Neji, Ali M. El-Rifaie, Zaher Al Barakeh
}

\begin{abstract}
Distracted driving can be defined as driving while being engaged in other activities that can reduce the driver's attention and focus on the road. Distraction has been always a major reason for car accidents. It can be identified by the driver's behaviour and the driving performance. Distraction factors can be classified as intended or unintended diversion of driver's concentration. Stress is a major factor of driving behaviour. It could be the consequence of personal life issues, excess of workload, or road conditions. The identification of distraction factors and stress level remains important and sometimes complicated. This paper presents a review of driver distraction and stress. It also identifies the most used distraction factors, and the latest detection methods and reduction techniques proposed and studied in different studies in the field. Moreover, a discussion about the strong relationship between driver distraction and stress is presented. Finally, a hybrid method is proposed.
\end{abstract}

Index Terms - Driver Distraction, Road Safety, Stress, Driving Conditions.

\section{INTRODUCTION}

As the number of vehicles increases in the world, traffic safety has become one of the main issues for governments and manufacturers. Enhancing road safety became a high priority objective nowadays. Driver distraction and lack of concentration are considered the major factor in car accidents. These accidents are not only counted as the number of injuries or loss of humans' lives, but also as the cost to the society and the infrastructure.

The task of driving requires continuous attention on the road, traffic circumstances and vehicle control. Drivers may pay insufficient attention to driving because they are preoccupied with other activities such as making a phone call, turning on/off the radio, listening to the radio, talking with a passenger or eating while driving. In addition, driver attention can be drawn by things or events inside and outside the car, like a crash on the other lane, a striking person on the pavement, a conspicuous billboard along the road, or a wasp in the car. Finally, when a driver is tired and not focused,

Raymond Ghandour, Electrical Engineering Department, American University of the Middle East, KUWAIT, +965 65937581

Bilel Neji, Electrical Engineering Department, American University of the Middle East, KUWAIT, +965 67636403

Ali M. El-Rifaie, Electrical Engineering Department, American University of the Middle East, KUWAIT, +965 51510805

Zaher Al Barakeh, Electrical Engineering Department, American University of the Middle East, KUWAIT, +965 65727493 he/she will be distracted. In addition to the above, a stressful driving condition may lead to unwanted situations. The stress occurs due to many reasons such as impaired driving, personal problems, excess of workload, traffic jam, etc.

This paper presents a review on the main factors, detection methods, and reduction of the driver distraction and stress. The following section presents the distraction factors. In the distraction detection methods section, the detection and reduction methods for driver's distraction are presented. Then stress detection and methods section' illustrates the driver stress factors, detection methods and reduction methods recently used in the literature. Discussion section presents a discussion about the strong relationship between the different driver's distraction factors and the stress. Finally, a conclusion and a proposal for future works to enhance road safety with new methodologies are presented.

\section{DISTRACTION FACTORS}

Distraction occurs when driver loses concentration as a consequence of being engaged in other activities. When a driver is distracted, a percentage of his/her concentration is shared with tasks that are not linked to driving. People cannot always safely multi-task, especially if the other activities are time consuming or complex. A safe driving environment should prevent drivers from being involved in other actions or tasks besides focusing on driving and should keep them away from any means of distraction. Distraction may cause the driver to become less observant or to make poor decisions about how to control the vehicle safely. This means that a driver is more likely to fail to anticipate hazards, and as a consequence, accidents can occur due to the distraction. Texting while driving is a common scenario of distraction that can lead to accidents. Talking to a passenger might reduce the driver's thinking resources, being shared between the driving situation, and the conversation taking place. Researchers classified distraction sources into two categories: internal distraction, and external distraction. Examples of internal distraction are eating, chatting, and using entertainment systems. External distraction can happen when a driver looks at the outside of his vehicle as well as roadside advertising panels. In addition, driver distraction can be classified into different types, most commonly auditory, biomechanical, cognitive, and visual.

\section{A. Auditory Distraction}

This type of distraction happens when disturbing sound tends to break, through selective attention, and impair cognitive performance. While attempting to focus on a driving, most of us, have had our attention drawn by extraneous sound. Even though a driver does his best to engage purposefully in driving, sounds often seem to intrude 
on his awareness, without invitation or control [1]. Evidently, these are instances in which our capacity to focus suffers some kind of breakdown. Examples of auditory distraction while driving include listening to music, listening to a radio conversation, and chatting with passengers.

\section{B. Biomedical Distraction (also referred as Physical Distraction)}

This type of distraction might happen when a driver is taking one or both of his hands off the steering for different reasons, including responding to a phone call [2], forwarding a message while driving, eating, adjusting vehicles settings, or controlling a GPS.

\section{Cognitive Distraction}

This kind of distraction keeps the driver's mind away from being focused on driving. If a distraction reduces the driver's awareness, then he/she will not be able to concentrate and fully focus on driving, and that can result in potential accidents The research in [3] states that even though drivers shift their attention based on the origins of the distractor, consistent disengagement from driving to attend to distractions is mostly driven by internal attention. Internal attention involves cognitive control processes and operates over representations in working memory, long-term memory, task rules, decisions, and responses [4]. Examples of cognitive driver distraction include conditions due to mental pressure, thinking about personal or financial issues, chatting with others, and/or using a cell phone [5].

\section{Visual Distraction}

This kind of distraction is the most frequent. It is caused by taking the driver's eyes off of the road. Checking a text message, viewing direction on a map, or looking outside while driving can result in visual distraction. These factors keep the driver away from focusing on driving [6].

While driving, multiple distraction types might happen simultaneously. As an example, entering a destination address on a GPS requires visual, cognitive, and biomechanical distraction types at once. When combined, these distraction types might lead to very dangerous situations.

\section{DistRaction Detection Methods}

\section{A. Distraction Sensing}

Several types of sensing modalities have been identified by researchers to detect driver distraction. The most known ones are vehicle control data, visual data, and physiological data.

Vehicle control data: Several vehicle control dynamics have been developed to track the effect of visual and internal distraction. This includes steering wheel reversal rate [7], throttle hold rate [8] and pedal position. The researchers in [9] introduced a solution to detect driver distraction using vehicle control data. They proposed specific patterns of steering wheel and pedals movements to be used to identify distracted driving. They also stated that during distraction, drivers tend to increase the distance to the leading vehicle or tend to drive faster than normal with no leading vehicle [9].

A variety of steering wheel metrics have been studied to detect abnormal patterns. This include standard deviation of steering wheel angle, steering wheel reversal rate, high frequency steering, and steering entropy [10]. A description of the listed metrics is presented in table I.

TABLE I

STEERING WHEEL METRICS

\begin{tabular}{|c|l|}
\hline $\begin{array}{c}\text { Steering wheel } \\
\text { metric }\end{array}$ & \multicolumn{1}{c|}{ Description } \\
\hline $\begin{array}{c}\text { Steering wheel } \\
\text { reversal rate [1] }\end{array}$ & $\begin{array}{l}\text { This method measures the number of steering } \\
\text { wheel reversals per minute. A second order } \\
\text { Butterworth low pass filter is used to filter the } \\
\text { steering wheel angle signal. Maximum steering } \\
\text { wheel reversal is calculated and is defined as the } \\
\text { largest steering wheel reversal. }\end{array}$ \\
\hline High frequency & $\begin{array}{l}\text { High frequency steering is sensitive to variations } \\
\text { in the primary and secondary task load. It is } \\
\text { steering [12] }\end{array}$ \\
$\begin{array}{l}\text { calculated as the total power in the frequency band } \\
\text { between 0.35 Hz and 0.6 Hz. Fast Fourier } \\
\text { transform is used to estimate the power spectral } \\
\text { density of the steering wheel signal. }\end{array}$ \\
\hline Steering entropy \\
[13] & $\begin{array}{l}\text { This method represents the predictability of } \\
\text { steering wheel movements. The entropy is } \\
\text { determined by down-sampling the steering wheel } \\
\text { signal to 4 Hz and using residuals from a one-step } \\
\text { prediction based on autoregressive modelling. }\end{array}$ \\
\hline
\end{tabular}

Visual data: are the most popular modality for detecting driver distraction. This type of data includes images and videos of the driver's facial expressions, head movements, eye ball movements, and body movements. Several methods using visual data have been developed to sense driver distraction, as presented in table II.

TABLE II

VISUAL DATA FOR DISTRACTION SENSING

\begin{tabular}{|c|l|}
\hline Reference & \multicolumn{1}{|c|}{ Visual data extraction methods } \\
\hline$[14]$ & $\begin{array}{l}\text { The driver expression such as yawning was used for } \\
\text { detecting distraction. }\end{array}$ \\
\hline$[15]$ & $\begin{array}{l}\text { The fraction of the eye closure was used to detect the } \\
\text { driver's drowsiness level. }\end{array}$ \\
\hline$[16],[17]$ & $\begin{array}{l}\text { The head position of the driver was used for distraction } \\
\text { detection. }\end{array}$ \\
\hline$[18]$ & $\begin{array}{l}\text { The frequency and duration of a driver's eye glances for a } \\
\text { secondary task are used to produce a total measurement of } \\
\text { eyes off the road. }\end{array}$ \\
\hline$[19]$ & $\begin{array}{l}\text { The facial features were used to detect the distracted eye } \\
\text { glance of the drivers. }\end{array}$ \\
\hline$[20]$ & $\begin{array}{l}\text { The distracted driving detection system based on gaze } \\
\text { direction and head position is introduced. }\end{array}$ \\
\hline$[21]$ & $\begin{array}{l}\text { The gaze direction was used to measure the distraction } \\
\text { classification. }\end{array}$ \\
\hline$[22]-[24]$ & $\begin{array}{l}\text { The infrared cameras were used to detect the driver's eyes } \\
\text { and the driver vigilance monitoring. }\end{array}$ \\
\hline$[25]$ & $\begin{array}{l}\text { The driver's right-hand movement was monitored to detect } \\
\text { distracted driving behaviours. }\end{array}$ \\
\hline
\end{tabular}

Physiological data: Brain activity signals and heart rate are examples of physiological data. They were used by authors in [26], [27] to detect driver's fatigue, which is a major factor of distraction. Usually, physiological data acquisition requires different sensors, which in many cases make the driver non comfortable especially when these sensors are setup around the driver's body. Nowadays, with the advances and development in nano technology, invasive methods could be used to embed micro and nano sensors in human bodies and collect physiological data [28]. The authors in [29], [30] proposed a body sensor network system that can help people providing healthcare services such as medical monitoring, memory enhancement, medical data access, and 
communication in emergency situations [29], [30]. Such system might contribute in the reduction of the driver distraction and hugely enhance physiological data collection process. Wireless sensors are being used instead of sensors with lead and cable connections, which in some cases contribute in increasing drivers' stress, and driving distraction. With wireless sensors, drivers are not restricted in their movements anymore, and can comfortably drive with less stress.

\section{B. Distraction Reduction Methods}

Different methods and algorithms were used for driver distraction detection. Table III summarizes some of the most recently employed techniques.

TABLE III

METHODS AND ALGORITHMS USED FOR DD DETECTION

\begin{tabular}{|c|l|}
\hline Reference & \multicolumn{1}{|c|}{ DD Algorithm Description } \\
\hline$[31]$ & Gaze direction and head orientation \\
\hline$[32]$ & Artificial neural network and gradient boosting machine. \\
\hline$[33]$ & Glance region prediction using random forest classifier. \\
\hline$[34]$ & $\begin{array}{l}\text { Dynamic Bayesian network outperformed logic } \\
\text { regression, static Bayesian network, and support vector } \\
\text { machine approaches in cognitive DD detection. }\end{array}$ \\
\hline$[35]$ & $\begin{array}{l}\text { Fuzzy expert system combined eye and face regions for } \\
\text { fatigue estimation }\end{array}$ \\
\hline$[36]$ & $\begin{array}{l}\text { Machine learning methods, in particular SVM, k-nearest } \\
\text { neighbour (k-NN), and graph-regularized extreme } \\
\text { learning machine. }\end{array}$ \\
\hline$[37]$ & $\begin{array}{l}\text { Component analysis, linear discriminate analysis, and } \\
\text { SVM. }\end{array}$ \\
\hline$[38]$ & $\begin{array}{l}\text { Probabilistic restricted Coulomb energy neural network } \\
\text { for drowsy driving prediction. }\end{array}$ \\
\hline
\end{tabular}

A variety of physiological attributes were also studied for driver distraction detection. Table IV lists some of the research that was conducted in this area.

TABLE IV

PSYCHOLOGICAL ATTRIBUTE FOR DD DETECTION

\begin{tabular}{|c|l|}
\hline Reference & \multicolumn{1}{|c|}{ Psychological Attribute method description } \\
\hline$[39]$ & $\begin{array}{l}\text { Brain activity measurement using } \\
\text { electroencephalographic signals: } \\
\text { Predict the start and the end of a distraction period using } \\
\text { an adaptive threshold-based prediction framework. }\end{array}$ \\
\hline$[40]$ & $\begin{array}{l}\text { Various machine learning methods: decision tree, } \\
\text { random forest, k-NN, SVM, and Naïve Bayes. }\end{array}$ \\
\hline$[41]$ & $\begin{array}{l}\text { Driver drowsiness detection using heart rate } \\
\text { electrocardiogram signals with LR (Logistic Regression) } \\
\text { and BN (Naïve Bayes). }\end{array}$ \\
\hline
\end{tabular}

Another way to detect driver distraction is to determine the driver's performance using an estimate of the vehicle dynamics. Table $\mathrm{V}$ summarizes some of the methods that were used for this purpose.

TABLE V

DRIVER PERFORMANCE FOR DD DETECTION

\begin{tabular}{|c|c|}
\hline Reference & Driver performance method description \\
\hline [42] & $\begin{array}{l}\text { Fuzzy system that personalizes the fuzzy membership } \\
\text { functions based on individual driving habits. The } \\
\text { system reflects user's preferences in the cruise control. }\end{array}$ \\
\hline [43], [44] & $\begin{array}{l}\text { DD detection with artificial NN and Gaussian mixture } \\
\text { model (GMM) using performance-based attributes. }\end{array}$ \\
\hline [45] & Double-class DD classifier based on GMM. \\
\hline [46] & $\begin{array}{l}\text { Vehicle dynamics and driving performance results } \\
\text { were engaged in the DD detection by an extreme } \\
\text { learning machine algorithm. }\end{array}$ \\
\hline [47] & $\begin{array}{l}\text { Driver behaviour prediction with dynamic } \mathrm{BN} \text { based } \\
\text { on preliminary collected data. }\end{array}$ \\
\hline
\end{tabular}

[48] $\quad$ Statistical signal processing and machine learning techniques, such as GMM, hidden Markov model (HMM), and BN were applied to simulate driver's behaviour like pedal orientation, car following, and lane change.

In the next section, the influence of stress on driving behaviour will be presented.

\section{Stress Detection ANd Methods}

Stress is a significant problem in daily life as it affects all types of population. It has drastic consequences on driver's behaviour since it is a major cause of a large number of road accidents. Stress is a major factor of driver distraction. A stressed driver can be seen concentrated on the road while he/she is really not. Stress need to be defined and modelled. Its modelling is very complicated. Many studies in the literature tried to define and model the stress and to propose evaluation methods for it.

\section{A. Stress Factors}

Successful driver performance is its ability to prevent vehicle crashes. It can be done by adapting his/her behaviour with respect to the changes in environment and complexity of the driving context. Unsuccessful driver performance causes more than $80 \%$ of the vehicle crashes that results in fatalities and injuries [49]. Driver performance is highly affected by stress in a negative way. It can cause traffic violations and crashes. Stress causes high mental workload and negative moods for drivers [50]. High mental workload result in a cognitive distraction which leads to deterioration of driver performance [51], [52].

Many stress factors such as negative mood, anger, aggressiveness, can lead to risky driving situations, such as high speed, lane departure, and running red lights. Chronic stress is also a dangerous stress type that affect the driving behaviour as it impacts the driver physical and mental health [53]. In addition of the above, table VI presents some additional stress factors.

TABLE VI

STRESS FACTORS AND EXAMPLES

\begin{tabular}{|c|ll|}
\hline Stress Factors & \multicolumn{1}{c|}{ Examples } \\
\hline $\begin{array}{c}\text { Driver Physical and } \\
\text { Mental Condition }\end{array}$ & $\bullet$ & Lack of sleep, driver fatigue [54] \\
& $\bullet$ & Driving phobia and impatience \\
\hline Road and Traffic & $\bullet$ & Congestion and heavy traffic [56] \\
Conditions & $\bullet$ & Motorist disturbances \\
\hline Vehicle Condition & $\bullet$ & Machine noise [56] \\
& $\bullet$ & Engine malfunction \\
\hline External Disturbance & $\bullet$ & Passengers in the vehicle [57] \\
& $\bullet$ & Mobile phones [58] \\
& $\bullet$ & In-car applications (Navigation error) \\
& $\bullet$ & Weather conditions (Low visibility, \\
& \multicolumn{2}{c}{ slippery road) [59] } \\
\hline
\end{tabular}

These factors are studied in the literature in order to propose methods to detect the stress and especially the stress level. In the following, we will present some of the methods used for stress detection.

\section{B. Stress detection methods}

The driver stress detection methods have also been studied in the literature by many authors. Many methods were 
proposed to detect the driver stress in order to reduce it. These methods were classified into four different categories:

- Questionnaire assessment

- Physiological based method

- Driving behaviour monitoring

- Visual based and speech detection

The questionnaire method was designed to build an inventory that defines driver's stress by many factors: driving aggression, dislike of driving, tension and frustration connected with successful and unsuccessful overtaking, irritation when overtaken and heightened alert and concentration. This method was studied in [60]. The authors associated a five-point scale for each of the factors $(0=$ Never, 1 = Rarely, 2 = Occasionally, $3=$ Frequently and $4=$ Very Frequently) to measure each inventory item. Many authors used this method such as the authors in [61]-[65]. This method presents some limitations. It is considered as subjective. In addition, a big variety of questions should be implemented.

The physiological based method relies on the use of sensors to detect the human's body physiological changes such as heart rate, muscle tension, respiration rate, electro dermal activity and brain activation [61], [66]. Physiological sensors record data during driving. Once a real time physiological change is detected, the driver will be provided with the information about his/her body conditions [67]. The recorded data is usually the electrocardiogram (ECG) data, the galvanic skin response (GSR), the skin conductivity, the skin temperature, the heart activity, the respiration and muscle activity [68]-[70]. These data were used to classify the drivers' stress level by several data analysis methods. The authors in [71]-[73] proposed different artificial neural network classifiers and a K-Nearest Neighbours (KNN) classifier to analyse and classify driver's stress into different levels (generally low, medium, and high). Statistical methods, such as root-mean square (RMS), zero crossing rate (ZCR), root mean quad (RMQ) and support vector machine (SVM) classifiers, applied on the EMG (Electromyography - muscle activity) signals to detect drivers' stress levels, are proposed in [74]-[76]. The physiological signals are considered as reliable indicators for detecting driver stress. Obtaining the signals involves obtrusive methods. In real-life driving situations, continuously wearing these sensors may not be practical, in addition to the problematic influence on accuracy and sensitivity along with being intrusive.

The driving behaviour monitoring can indicate the stress level of a driver. In this method, the stress level is detected based on the vehicle velocity and the steering wheel data [73], [77], [78]. Many sensors were used to acquire these data such as: GPS unit, cameras and ranging sensors (ultrasonic and laser sensors). These sensors were installed in the vehicle to observe the driver behaviour. They can monitor the turning patterns of the steering wheel and recognize lanes and accelerating patterns. Comparing these data with a reference data acquired for a normal driving condition can detect the stress level of a driver. This method has some limitations related to the vehicle type, driver experience and road conditions that can affect the data acquisition.

The visual based detection method consists on the installation of the visual-based sensors in the vehicle, rather than on the driver body, to detect the physiological data. This method' sensors have a great potential of measuring driver stress since they are non-invasive and can detect the stress evolution in real-time. The visual-based sensors are usually used for the thermography where they can detect the skin temperature, and pupil dilatation [79], [80]. They proved that pupil diameter and skin temperature are increasing during stressful events. Other visual-based methods are used and are based on the detection of the facial expression by a NIR-Camera. Therefore a computer vision technology is used to accurately detect the face and acquire the data [81], [82]. The visual-based method is limited by the easily disturbance when occlusion or illumination changes appears.

The speech recognition method is used in [83] and [84] to determine the driver stress by analysing the changes in pitch in a subject's speech. These changes are then detected by the use of signal processing methods. This method is limited by the fact that it can be a distraction for the driver.

Many of these detection methods were proposed and applied in the literature to detect and identify the drivers' stress level in order to propose methods for reducing it. The next section will present a review of stress reduction methods.

\section{Stress reduction methods}

Once stress is detected, the next step is to reduce it in order to improve driver performance and road safety. In the literature, the reduction methods were classified into three categories: the driver assistance systems, the notification alert, and the environmental soothing.

The driving assistance systems assist or take over a part of the driving task to reduce or even eliminate drivers' errors [85]. They use ranging sensors such as ultrasonic sensors, radar sensors, laser scanner sensors, etc. These sensors, installed in the vehicle, capture data from the driving environment and observe surrounding conditions [86]. The data is then analysed. The system will assist the driver to perform the driving task easily [87]. Several examples of these types of systems were implemented in the recently manufactured vehicles, such as, the APA (Active Park Assist), the ACC (Active Cruise Control), and the ACS (Active City Stop).

The notification alert system is a warning system that notifies the driver when a driving problem is detected [88]. Two types were identified from the literature: the notification alert on the driver physiological condition and the notification alert on the road situation. The driver will be alerted when his/her stress level is high or increasing to the high limit, and the system will request the decrease of the vehicle speed to maintain a safe driving. On the other hand, road situation notification alert warns the driver on the road condition and when hazard is detected, such as a lane departure. This alert is based on the data acquired from several sensors such as cameras and lidars to detect the lanes and the data is processed via image processing algorithms to detect the stress driving situation.

The environment soothing is a system based on the physiological stress detected by the physiological sensors and identified by signal processing methods and machine learning methods [89]. Once a high stress level is detected, an environment soothing application will be launched to reduce it and to ensure a safely driving condition.

Innovation Europe and Faurecia Automobile Seating proposed an intelligent car seat that measures and monitors the driver physiological status [89]. This system is embedded in the vehicle and do not cause any disturbance to the driver. 
Once the system detects a driver high-level stress, a relaxation massage and warm ventilation equipped inside the driver seat are activated to soothe the driver [89]. Another type of soothing environment system is proposed in [90]. It is a smart music player that plays the driver's preferred music when the stress level is high.

These stress reduction methods present many limitations. The drivers usually have some difficulties following the instructions of the driving assistance systems because of their unfamiliarity and the non-trust. Notification alert may not always reduce the drivers' stress level because the drivers know that $0 \%$ failure of these systems is unrealistic. This can increase the stress level for some drivers under certain conditions.

Soothing environment techniques adjust the in-vehicle surrounding according to each driver case. The generalization of these techniques is challenging since the interaction of each driver with these techniques is different.

In the next section, we will discuss the limitations of these methods, and we will propose a method for driver distraction and stress reduction.

\section{DISCUSSION}

After the presentation of the different factors and methods related to driver distraction and stress, the relationship between them is discussed in the next subsection. In addition, a proposal for improving driver concentration and road safety is presented.

\section{A. Distraction vs. Stress}

The distraction factors, external or internal, influence the driver behaviour. As mentioned in the previous sections, it is widely studied. Most of the studies were concentrating in more than one type of distraction.

Stress is also studied, but separately from other types of distraction. It is true that some stress factors are different from the normal driver distraction methods such as the personal problems and the excess of workload, but they lead to the same ending which is a driver distraction.

After doing this study and this review, we found that stress is a major factor, in fact, one of the most critical factors in driving conditions. The reasons for a driver to be stressed are numerous, and the stress detection is more complex than the other types of distractions. For example, we can have a driver completely concentrated on the road, but he/she is thinking about something else, and, not completely concentrating on driving. A camera or other non-invasive sensors have limitations in the stress level detection. In addition, invasive sensors, used to detect the physiological status of the driver can increase the level of stress as well as the non-concentration on the road and the driver distraction.

All the factors associated to the distraction mentioned in the previous sections are detected separately from stress, while they can be associated to a certain stress level. In this case, the reduction methods should cover the stress factor in order to be more performant.

\section{B. Distraction and stress reduction proposal}

In order to reduce the driver stress and any other distraction types, this paper proposes a general hybrid method with some characteristics that are essential for the driver acceptance and trust. This method should be based on the following:

- Non-invasive sensors;

- Sensors installation not disturbing the driver;

- Estimation of the important parameters requiring measurements from invasive sensors;

- Modelling of the relationship between stress and other distraction factors;

- Usage of machine learning methods, in addition to logic methods to analyse the data acquired;

- Development of a hybrid system based on the above to evaluate many types of stress and distraction.

This method is identified to answer most of the limitations. The use of the non-invasive sensors where their installation is not disturbing the driver, is essential. Therefore, the driver will drive comfortably without the feeling of being recorded and/or supervised. The parameters' estimation can solve the problem of invasive sensors usage. The modelling of the relationship between stress and other driver distraction types answer the correlation between all factors. The usage of machine learning and logic methods is essential to combine between all of the above points in a way that the resulting system can cover many factors at the same time. The combination of different learning and estimation methods will result in a hybrid system that resolves the limitations and improves the driving performance.

\section{CONCLUSION}

In this paper, a general review of the driver distraction methods is presented. Driver distraction factors, detection methods and reduction techniques are listed as studied in the literature. The driver's stress factors, detection methods and reduction methods were also presented. We discussed the strong relationship between the stress and the other distraction factors and the actual non combination between them that led to the limitations in the performance of the reduction methods. It could be concluded that stress and other distraction factors should be treated together as one distraction system. This overview on the different factors and methods led us to deeply understand the problem we are facing every day and to propose a method to solve it. This method will be an evolution of the existing methods since it is designed to answer many limitations as presented in this paper.

For future works, we are planning to implement this method, test it, and prove its performance. A set of non-invasive sensors will be identified and used to collect data. These data will be used in the estimation, modelling, learning, and classification processes to test the proposed method validity and performance.

\section{REFERENCES}

[1] S.P. Banbury, W.J. Macken, S. Tremblay, and D.M. Jones, “Auditory Distraction and Short-Term Memory: Phenomena and Practical Implications", Journal of Human Factors, vol. 43, no.1, 2001, pp. $12-29$

[2] "Understanding the distracted brain: Why driving while using hands-free phones is risky behavior", Nat. Safety Council, Itasca, IL, USA, White Paper 0412 000082045, 2012.

[3] N.M. Yuzoff, R.F. Ahmad, C.Guillet, A.S. Malik, and N.M. Saad "Selection of Measurement Method for Detection of Driver Visual 
Cognitive Distraction: A Review", IEEE Access, vol. 5, 2017, pp.22844-22854.ff10.1109/ACCESS.2017.2750743ff.ffhal-01712800.

[4] M.M. Chun, J.D. Golomb, and N.B. Turk-Browne, "A taxonomy of external and internal attention", Annual Review of Psychology, vol. 62, Jan. 2011, pp. 73-101.

[5] H. Farah, S. Zatmeh, T. Toledo, and P. Wagner, "Impact of distracting activities and drivers' cognitive failures on driving performance", Advances in Transportation Studies, vol 1. 2016, pp. 71-82.

[6] A. Calvi, A. Benedetto, and F. D'Amico, "Effects of mobile telephone tasks on driving performance: A driving simulator study", Advances in Transportation Studies, vol. 26. 2012, pp. 29-44. 10.4399/97888548465863.

[7] W.A. MacDonald, and E.R. Hoffman, "Review of relationships between steering wheel reversal rate and driving task demand", Journal of Human factors, vol. 22, no. 6, 1980, pp. 733-739.

[8] B. Zylstra, O. Tsimhoni, P.A. Green, and K. Mayer, "Driving performance for dialing, radio tuning, and destination entry while driving straight roads", MI: The University of Michigan Transportation Research Institute, Ann Arbor, 2003

[9] L. Jin, Q. Niu, H. Hou, H. Xian, Y. Wang, and D. Shi, "Driver cognitive distraction detection using driving performance measures", Discrete Dynamics in Nature and Society, 2012.

[10] K. Kircher, and C. Ahlstrom, "Predicting visual distraction using driving performance data", Annals of advances in automotive medicine, Association for the Advancement of Automotive Medicine, Annual Scientific Conference, vol. 54, 2010, pp. 333-342.

[11] J. Ostlund, B. Peters, B. Thorslund, J. Engström, G. Markkula, A. Keinath, and G. Markula, "Driving performance assessment - methods and metrics", Technical report, December 2005.

[12] J.R. McLean, and E.R. Hoffmann, "Analysis of Drivers' Control Movements", Journal of Human Factors, vol. 13, no. 5, 1971, pp $407-418$

[13] E. Boer, M. Rakauskas, N. J. Ward, and M. A. Goodrich, "Steering entropy revisited", 3rd Int. Driving Symposium on Human Factors in Driver Assessment, Rockport, Maine, 2005.

[14] Q. Ji, Z. Zhu, and P. Lan, "Real-time nonintrusive monitoring and prediction of driver fatigue", IEEE Trans. Vehicular Technology, vol. 53, no. 4, 2004, pp. 1052-1068.

[15] P.R. Tabrizi, and R.A. Zoroofi, "Drowsiness detection based on brightness and numeral features of eye image", Fifth Int. Conf. on Intelligent Information Hiding and Multimedia Signal Processing, Kyoto, Japan, 2009, pp. 1310- 1313.

[16] E. Murphy-Chutorian, A. Doshi, and M.M. Trivedi, "Head pose estimation for driver assistance systems: a robust algorithm and experimental evaluation". IEEE Intelligent Transportation Systems Conference, Seattle, Washington, USA, 2007, pp. 709-714.

[17] G. Sun, Y. Jin, Z. Li, F. Zhang, and L. Jia, "A vision-based head status judging algorithm for driving fatigue detection system", Advances in Transportation Studies, 2015, pp.51-64.

[18] E. Farber, J. Foley, and S. Scott, "Visual attention design limits for its in-vehicle systems: the society of automotive engineers standard for limiting visual distraction while driving". Transportation Research Board Annual General Meeting, USA, 2000, pp. 2-3.

[19] S. Park, and M. Trivedi, "Driver activity analysis for intelligent vehicles: issues and development framework". IEEE Proc. Intelligent Vehicles Symposium, Las Vegas, Nevada, USA, 2005, pp. 644-649.

[20] J. Pohl, W. Birk, and L. Westervall, "A driver-distraction-based lane-keeping assistance system", Proc. of the Institution of Mechanical Engineers, Part I, J. of Systems and Control Engineering, vol. 221, no.4, 2007, pp. 541-552.

[21] K. Kircher, C. Ahlstrom, and A. Kircher, "Comparison of two eye-gaze based real time driver distraction detection algorithms in a small-scale field operational test". Proc. Fifth Int. Symp. on Human Factors in Driver Assessment, Training and Vehicle Design, Big Sky, Montana, USA, 2009, pp. 16-23.

[22] L.M. Bergasa, J. Nuevo, M.A. Sotelo, R. Barea and M.E. Lopez, "Real-time system for monitoring driver vigilance", IEEE Trans. on Intelligent Transportation Systems, vol. 7, no. 1, 2006, pp. 63-77.

[23] Q. Ji, P. Lan, and C. Looney, "A probabilistic framework for modeling and real time monitoring human fatigue", IEEE Trans. on Systems Man and Cybernetics, Part A, Systems and Humans, vol. 36, no. 5, 2006, pp. $862-875$.
[24] C. Craye, and F. Karray, "Multi-distributions particle filter for eye tracking inside a vehicle", Image Analysis and Recognition, vol. 6 , 2013, pp. 407-416.

[25] C. Craye, and F. Karray, "Driver distraction detection and recognition using RGB-D sensor", Computing Research Repository, 2015, abs/1502.00250. Available at: http:// arxiv.org/abs/1502.00250

[26] L. Shiwu, W. Linhong, Y. Zhifa, J. Bingkui, Q. Feiyan, and Y. Zhongkai, "An active driver fatigue identification technique using multiple physiological features", Int. Conf. on Mechatronic Science, Electric Engineering and Computer (MEC), Jilin, China, 2011, pp 733-737.

[27] S.K. Lal, and A. Craig, "Driver fatigue: electroencephalography and psychological assessment", Psychophysiology, vol. 39, no. 3, 2002, pp 313-321.

[28] B. Neji, J. Xu, A.H. Titus, and J. Meltzer, "Micro-fabricated DC comparison calorimeter for RF power measurement", Sensors, vol. 14 no. 11, 2014, pp. 20245-20261, doi:10.3390/s141120245

[29] V. Leonov, P. Fiorini, S. Sedky, T. Torfs, and C. Van Hoof, "Thermoelectric MEMS generators as a power supply for a body area network", Proceedings of the 13th International Conference on Solid-State Sensors, Actuators and Microsystems, Seoul, Korea, pp 291-294, 2005, June 5-9.

[30] A. Darwish, and A.E. Hassanien, "Wearable and implantable wireless sensor network solutions for healthcare monitoring", Sensors (Basel, Switzerland), vol. 11, no. 6, 2011, pp. 5561-5595, doi: 10.3390/s 110605561

[31] C. Ahlstrom, K. Kircher, and A. Kircher, "A gaze-based driver distraction warning system and its effect on visual behavior," IEEE Trans. on Intelligent Transportation Systems, vol. 14, no. 2, June 2013 pp. 965-973

[32] X.-P. Huynh, S.-M. Park, and Y.-G. Kim, "Detection of driver drowsiness using 3D deep neural network and semi-supervised gradien boosting machine," in Proc. Asian Conference on Computer Vision, in Lecture Notes in Computer Science, Taipei, Taiwan, vol. 10118 Springer, 2016, pp. 134-145.

[33] L. Fridman, P. Langhans, J. Lee, and B. Reimer, "Driver gaze region estimation without use of eye movement," IEEE Intelligent Systems, vol. 31, no. 3, May/Jun. 2016, pp. 49-56.

[34] A. Azman, S.Z. Ibrahim, Q. Meng, and E.A. Edirisinghe, "Physiological measurement used in real time experiment to detect driver cognitive distraction," in Proc. Int. Conf. Electron., Inf. Commun. (ICEIC), Kota Kinabalu, Malaysia, January 2014, pp. 1-5.

[35] M.-H. Sigari, M. Fathy, and M. Soryani, "A driver face monitoring system for fatigue and distraction detection," Int. J. of Vehicular Technology, vol. 2013, January 2013, Art. no. 263983, doi: $10.1155 / 2013 / 263983$.

[36] Y. Jiao, Y. Peng, B.-L. Lu, X. Chen, S. Chen, and C. Wang, "Recognizing slow eye movement for driver fatigue detection with machine learning approach," in Proc. Int. Joint Conf. Neural Networks (IJCNN), Beijing, China, Jul. 2014, pp. 4035-4041.

[37] J. Jo, S.J. Lee, J. Kim, H. Gi Jung, and K.R. Park, "Vision based method for detecting driver drowsiness and distraction in driver monitoring system," Optical Engineering, vol. 50, no. 12, 2011, pp. 1-24.

[38] H. Matsuo and A. Khiat, "Prediction of drowsy driving by monitoring driver's behavior," in Proc. 21st Int. Conf. Pattern Recognition (ICPR), Tsukuba, Japan, Nov. 2012, pp. 3390-3393.

[39] S. Wang, Y. Zhang, C. Wu, F. Darvas, and W.A. Chaovalitwongse, "Online prediction of driver distraction based on brain activity patterns," IEEE Trans. Intelligent Transportation Systems, vol. 16, no. 1, Feb. 2015, pp. 136-150.

[40] V. Alizadeh and O. Dehzangi, "The impact of secondary tasks on drivers during naturalistic driving: Analysis of EEG dynamics," in Proc. IEEE 19th Int. Conf. Intell. Transp. Syst. (ITSC), Rio de Janeiro, Brazil, Nov. 2016, pp. 2493-2499.

[41] M. Babaeian, N. Bhardwaj, B. Esquivel, and M. Mozumdar, "Real time driver drowsiness detection using a logistic-regression-based machine learning algorithm," in Proc. IEEE Green Energy Syst. Conf. (IGSEC) Long Beach, CA, USA, Nov. 2016, pp. 1-6.

[42] S. Qiu, R. McGee, and Y.L. Murphey, "Adaptive fuzzy prediction for automotive applications usage," in Proc. IEEE 14th Int. Conf. Mach. Learn. Appl. (ICMLA), Miami, FL, USA, Dec. 2015, pp. 19-24.

[43] S. Choi, J. Kim, D. Kwak, P. Angkititrakul, and J.H.L. Hansen, "Analysis and classification of driver behavior using in-vehicle CAN-bus information," in Proc. Int. Conf. Multimedia Expo (ICME), Barcelona, Spain, 2011, pp. 1-6. 
[44] S. Im, C. Lee, S. Yang, J. Kim, and B. You, "Driver distraction detection by in-vehicle signal processing," in Proc. IEEE Symp. Comput. Intell. Vehicles Transp. Syst. (CIVTS), Orlando, FL, USA, Dec. 2015, pp. 64-68.

[45] J. Yang, T.N. Chang, and E. Hou, "Driver distraction detection for vehicular monitoring," in Proc. 36th Annu. Conf. IEEE Ind. Electron. Soc. (IECON), Glendale, AZ, USA, Nov. 2010, pp. 108-113.

[46] V. Martínez, I. Del Campo, J. Echanobe, and K. Basterretxea, "Driving behavior signals and machine learning: A personalized driver assistance system," in Proc. IEEE 18th Int. Conf. Intell. Transp. Syst., Las Palmas, Spain, Sep. 2015, pp. 2933-2940.

[47] T. Kumagai and M. Akamatsu, "Prediction of human driving behavior using dynamic Bayesian network," IEICE Trans. Inf. Syst., vol. E89-D, no. 2, 2006, pp. 857-860.

[48] C. Miyajima and K. Takeda, "Driver-behavior modeling using on-road driving data: A new application for behavior signal processing," IEEE Signal Process. Mag., vol. 33, no. 6, Nov. 2016, pp. 14-21.

[49] N. A. Stanton and P.M. Salmon, "Human error taxonomies applied to driving: A generic driver error taxonomy and its implications for intelligent transport systems", in Safety Science, vol. 47, no. 2, 2009, pp. 227-237.

[50] C. Frasson, P.O. Brosseau, and T.H.D. Tran, "Virtual environment for monitoring emotional behavior in driving" in Intelligent Tutoring Systems, Springer, 2014, pp. $75-83$.

[51] H. Wiberg, E. Nilsson, P. Lindén, B. Svanberg, and L. Poom, "Phsycological responses related to moderate mental load during car driving in field conditions" in Biological Psychology, vol. 108, 2015, pp. $115-125$.

[52] J.-M. Girard, K. Younsi, J. Floris, P. Simon, P. Loslever, and J.-C. Popieul, "An analysis of driving performance evolution under high workload conditions", Advances in Transportation Studies, 2010, pp. 49-58.

[53] R.M. Baevski, A.P. Berseneva, E.Y. Bersenev, and A.K. Eshmanova. "Use of principles of prenosological diagnosis for assessing the functional state of the body under stress conditions as exemplified by bus drivers". Human Physiology, vol. 35, no. 1, 2009, pp. 34-42.

[54] M.A. Kompier, and V. Di Martino. "Review of bus drivers" occupational stress and stress prevention". Stress Medicine, vol. 11, no. 1, 1995, pp. 253-262.

[55] C. Schieß1. "Stress and strain while driving," in Proc. European Conf. Transport Research Institutes, 2007, pp. 1-11.

[56] D. L. Wiesenthal, D. A. Hennessy, and B. Totten. "The influence of music on driver stress," J. Applied Social Psychology, vol. 30, 2000, pp. 1709-1719.

[57] I. Engström. "Young Drivers and Their Passengers Crash Risk and Group Processes," Ph. D. Dissertation. Linköping University. Linköping, Sweden, 2008.

[58] B. Reimer, B. Mehler and J.F. Coughlin. "An evaluation of driver reactions to new vehicle parking assist technologies developed to reduce driver stress," Cambridge: New England University Transportation Center, Massachusetts Institute of Technology, 2010.

[59] J. B. Hu, A. Li and W.L. Wang. "Analysis on driver's driving workload in different weather conditions," J. Beijing University of Technology vol. 37, no. 4, 2011.

[60] S. Mcleod. "Likert Scale," Simply Psychology, 2017

[61] B. Mehler, B. Reimer, J. Coughlin, and J. Dusek, "Impact of incremental increases in cognitive workload on physiological arousa and performance in young adult drivers," Transportation Research Record: J. Transportation Research Board, vol. 2138, no. 1, 2009, pp. 6-12.

[62] R. Costin, C. Rotariu, and A. Pasarica, "Mental stress detection using heart rate variability and morphologic variability of EeG signals," in Proc Int. Conf. and Exposition on Electrical and Power Engineering, Iasi, Romania, 2012

[63] G. Funke, G. Matthews, J.S. Warm and A.K. Emo, "Vehicle automation: A remedy for driver stress?" Ergonomics, vol. 50, no. 8, 2007, pp. 1302-1323.

[64] A. Pauzié, "Evaluating driver mental workload using the driving activity load index (DALI)," in Proc. European Conf. Human Interface Design for Intelligent Transport Systems, Berlin, Germany, 2008.

[65] A. Pauzié, "Method to evaluate driver's workload in real road context," in Proc. Int. Conf. Digital Human Modeling, San Diego, California, USA, 2009.

[66] N. Munla, M. Khalil, A. Shahin, and A. Mourad, "Driver stress level detection using HRV analysis," in Proc. Int. Conf. Advances in Biomedical Engineering (ICABME), Beirut, Lebanon, 2015.
[67] J. F. Coughlin, B. Reimer, and B. Mehler, "Driver Wellness, Safety \& the Development of an Awarecar", AgeLab, Massachusetts Institute of Technology, Cambridge, Massachusetts, USA, 2009.

[68] J. A. Healy, and R. W. Picard, "Detecting stress during real-world driving using physiological sensors," IEEE Trans. Intelligent Transportation Systems, vol. 6, no. 2, 2005, pp. 156-166.

[69] Y. Barniv, M. Aguilar, and E. Hasanbelliu, "Using EMG to anticipate head motion for virtual-environment applications," IEEE Trans. Biomedical Engineering, vol. 52, no. 6, 2005, pp.1078-1093.

[70] H. Kurniawan, A. V. Maslov, and M. Pechenizkiy, "Stress detection from speech and galvanic skin response signals," in Proc. 26th IEEE Int. Symp. Computer-Based Medical Systems, Porto, Portugal, 2013.

[71] J.-S. Wang, C.-W. Lin, and Y.-T. C. Yang, "A k-nearest-neighbor classifier with heart rate variability feature-based transformation algorithm for driving stress recognition", Neurocomputing, vol. 116 , 2013, pp.136-143.

[72] R. R. Singh, S. Conjeti, and R. Banerjee, "A comparative evaluation of neural network classifiers for stress level analysis of automotive drivers using physiological signals," Biomedical Signal Processing and Control, vol. 8, no. 6, 2013, pp.740-754.

[73] A. Lanatà, G. Valenza, A. Greco, C. Gentili, R. Bartolozzi, F. Bucchi, and E.P. Scilingo, "How the autonomic nervous system and driving style change with incremental stressing conditions during simulated driving," IEEE Transactions on Intelligent Transportation Systems, vol. 16, no. 3, 2015, pp. 1505-1517.

[74] K. Soman, A. Sathiya, and N. Suganthi, "Classification of stress of automobile drivers using radial basis function kernel support vector machine," In 2014 International Conference on Information Communication and Embedded Systems (ICICES'14), 2014, pp. 1-5.

[75] R. Zheng, S. Yamabe, K. Nakano, and Y. Suda, "Biosignal analysis to assess mental stress in automatic driving of trucks: Palmar perspiration and masseter electromyography," Sensors, vol. 15, no. 3, 2015, pp.5136-5150.

[76] D. Katsis Christos, Y. Goletsis, G. Rigas, and D. I. Fotiadis, "A wearable system for the affective monitoring of car racing drivers during simulated conditions," Transportation Research Part C: Emerging Technologies, vol. 19, no. 3, 2011, pp.541-551.

[77] D. S. Lee, T. W. Chong, and B. G. Lee, "Stress events detection of driver by wearable glove system”, IEEE Sensors Journal, vol. 17, no. 1, 2017 , pp. 194-204

[78] A. Mas, F. Merienne, and A. Kemeny, "Lateral control assistance and driver behavior in emergency situations", Advances in Transportation Studies, 2011, 10.4399/978885484657914.

[79] M. Pedrotti, M. A. Mirzaei, A. Tedesco, J. R. Chardonnet, F. Merienne, S. Benedetto, and T. Baccino, "Automatic stress classification with pupil diameter analysis," Int. J. Human-Computer Interaction, vol. 30, no. 3, 2014, pp. 220-236.

[80] S. Baltaci, and D. Gokcay, "Stress detection in human-computer interaction: Fusion of pupil dilation and facial temperature features,' Int. J. Human- Computer Interaction, vol. 32, no. 12, 2016 , pp. $956-966$.

[81] A. Fernández, R. Usamentiaga, J. L. Carús, and R. Casado, "Driver distraction using visual-based sensors and algorithms", Sensors, vol. 16, no. 11, 2016, pp. 1805.

[82] H. Gao, A. Yüce, and J. P. Thiran, "Detecting emotional stress from facial expressions for driving safety," in Proc. IEEE Int. Conf. Image Processing (ICIP), Paris, France, 2014.

[83] H. Boril, S. O. Sadjadi, T. Kleinschmidt, and J. H. Hansen, "Analysis and detection of cognitive load and frustration in drivers' speech," in Proc. Eleventh Annual Conf. Int. Speech Communication Association, Chiba, Japan, 2010.

[84] B. Yin, N. Ruiz, F. Chen, and M. A. Khawaja, "Automatic cognitive load detection from speech features," in Proc. 19th Australasian Conf. Computer Human Interaction: Entertaining User Interfaces, Adelaide, Australia, 2007

[85] K. A. Brookhuis, D. De Waard, and W. H. Janssen, "Behavioural impacts of advanced driver assistance systems - An overview," European J. Transport and Infrastructure Research vol. 1, no. 3, 2001 , pp.245-253.

[86] B. Reimer, B. Mehler, and J. F. Coughlin "Reductions in self-reported stress and anticipatory heart rate with the use of a semi-automated parallel parking system," Applied ergonomics, vol. 52, 2016, pp.120-127.

[87] T. C. Harrison Ford, "What is Ford Active City Stop?", 2017. 
[88] B. Howard, "What is lane departure warning, and how does it work?", Extreme Tech, 2017.

[89] M. Stock, "Intelligent Car Seat Detects Driver's Stress Level", Reuters, 2015.

[90] D. L. Wiesenthal, D. A. Hennessy, and B. Totten, "The influence of music on driver stress," J. Applied Social Psychology, vol. 30, 2000, pp.1709-1719.

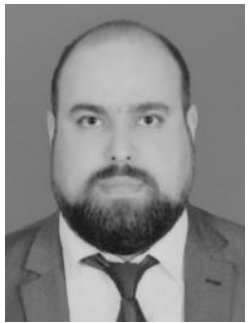

Raymond Ghandour received the B.Eng. degree in computer and communication engineering from Holy Spirit University, Kaslik, Lebanon, in 2007, the M.S. degree in industrial control from Lebanese University, Beirut, Lebanon, in 2008, the M.S. degree in science of technology and information from the University of Technology of Compiegne, France in 2008 and the Ph.D. degree in automatic control at the University of Technology of Compiegne, France, in 2011. In December 2011, he started a post-doctoral position from the University of Valenciennes and Hainaut-Cambresis UVHC, Valenciennes, France. In December 2012, he started a post-doctoral position at the CETIM and the University of Technology of Compiegne. He joined ALTRAN Group ALTRAN Technologies - North Division, Lille, France, as the director of Research and Development in April 2013. He is currently an assistant professor at the American University of the Middle East, Kuwait. He has been conducting research in different areas including control of hybrid vehicles, vehicle dynamics, signal processing, driving assistance systems and modelling and control of nonlinear systems.

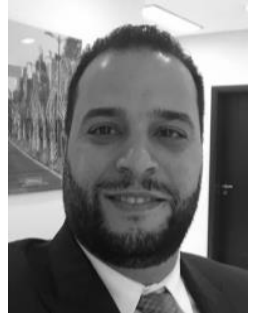

Bilel Neji received the B.Eng. degree in electrical engineering from Sfax University, Tunisia, in 2007 , the M. Sc. degree in new technologies in computer systems from Sfax University, Tunisia, in 2008, and the Ph.D. degree in electrical engineering from the State University of New York at Buffalo, USA, in 2015. He joined BAK USA Technologies, New York, USA, as Director of Engineering in 2014. He is currently an assistant professor at the American University of the Middle East, Kuwait. He has been conducting research in different areas including embedded systems, and MEMS \& sensors design and micro fabrication.

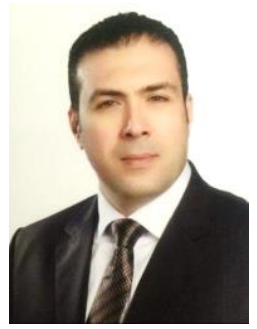

Ali M. El-Rifaie received the B.Sc. degree in electrical power and machines in 1998, the M.Sc. degree in electrical Power system engineering in 2005, and the $\mathrm{PhD}$ in Power System Protection from Helwan University-Egypt in 2011. In the year 2005 he started working at the Egyptian National Institute for Standards for ten continuous years where he worked for the High voltage department and was concerned with high voltage, electrical energy meters and electromagnetic compatibility measurements and applications. He joined the American University of the Middle East in Kuwait (AUM) in Sep. 2015. Currently he is an associate professor and senior member in IEEE. He has been conducting research in the fields of Power system Protection, smart grids, Energy management renewable Energy and Electrical Metrology.

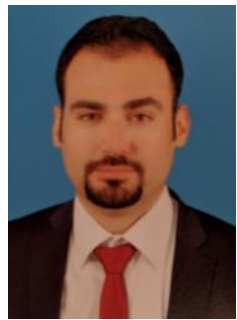

Zaher Al Barakeh received his $\mathrm{PhD}$ in Process Engineering in 2012. The subject of his $\mathrm{PhD}$ was "air pollution monitoring by multi-sensor system - mixed method of classification and determination of pollution index". After his $\mathrm{PhD}$, he worked as engineer in "Azimut Monitoring", French company specialized in air monitoring. And currently holds the position of assistant professor at the American University of the Middle east (AUM) in the Electrical Engineering department. His activity is focused on data fusion, multi-variate modelling, and environmental monitoring. 